antigens. The incidence of HLA alloimmunisation in our study is comparable with that reported by Polesky ${ }^{1}$ and Perkins ${ }^{2}$ for similar groups of patients receiving frozen blood as the only antigenic stimulus. By including appropriate immunofluorescence tests our study has shown that platelet and granulocyte specific antibodies are more common in these patients (37\%) than HLA antibodies $(10 \%)$. This pattern of immunisation may reflect differences in the residual amounts of antigenic material in the transfused frozen blood and the relative antigenicity of the different cells.

These findings and the doubt whether pretransplant transfusion of frozen blood protects against graft rejection to the same extent as does whole blood suggest that there is little advantage in using frozen blood in potential kidney transplant recipients. Platelet and granulocyte specific antibodies are unlikely to affect renal transplantation, but immunisation against these antigens may significantly affect the results of bone marrow transplantation. ${ }^{5} \mathrm{~A}$ transfusion policy for prospective bone marrow transplant recipients should take into account this potential immunogenic effect of frozen blood.

AHW received a grant from St Bartholomew's Hospital Joint Research Board.

${ }^{1}$ Polesky HF. Clinical problems with HLA sensitisation. In: Frozenthawed red blood cells. New York: Alan R Liss, 1976:141-55.

2 Perkins HA. HLA antigens and blood transfusion: effect on renal transplants. Transplant Proc 1977;9, Suppl 1 :229-32.

3 Jenkins WJ, Blagdon J. The longterm storage of blood for transfusion using an improved container for freezing the red cells in liquid nitrogen. fClin Pathol $1971 ; 24: 685-9$.

${ }^{4}$ Amer KA, Pepper DS, Urbaniak SJ. Lymphocyte, granulocyte and platelet contamination of blood frozen by the low-glycerol liquid nitrogen technique. Brf Haematol 1980;44:253-61.

5 Blaschke J, Sorensen RU, Thompson JS, Polmar SH. Clinical relevance of granulocytotoxic antibodies in human transplantation. Transplant Proc 1977;9:1899-1901.

(Accepted 18 April 1980)

St Bartholomew's Hospital and Medical College, London EC1A 7BE R M MINCHINTON, FAIMLS, research assistant, blood transfusion laboratory

A H WATERS, PHD, FRCPATH, reader in haematology and consultant haematologist

L R I BAKER, MD, FRCP, consultant nephrologist

W R CATTELL, MD, FRCP, consultant nephrologist

\section{Effect of age on pelvic inflammatory disease in nulliparous women using a copper 7 intrauterine contraceptive device}

The introduction of copper intrauterine contraceptive devices (IUCDs) in the early 1970s was an innovation as their small size and consequent ease of insertion meant that they could be used by nulliparous women, a group for whom IUCDs had been contraindicated. Recently, however, the use of IUCDs by nulliparae has been questioned. This is partly because of the associated risk of pelvic inflammatory disease, which may lead to infertility. ${ }^{1}$ We report on factors affecting the incidence of this disease in a sample of nulliparous women using the copper 7 IUCD.

\section{Patients, methods, and results}

Between July 1975 and June 1976, 871 nulliparous women aged 16-49 attending the Margaret Pyke family planning clinic had an IUCD (copper 7) inserted for the first time. None showed clinical evidence of pelvic inflammatory disease at the time of insertion. A check up was advised at three months and then every six months. Women who missed an appointment were written to immediately. If they did not respond a duplicate letter was sent during the next month. At each visit side effects and information about pregnancy, expulsion, and removal were noted and the patient examined by the attending doctor for clinical evidence of pelvic inflammatory disease. Symptoms ranged from mild dyspareunia and pelvic tenderness to those severe enough to warrant hospital admission. Life-table analyses were used to calculate net rates for the disease for the first segment of IUCD use.
The disease was diagnosed in 54 women during the 30 months after insertion. The incidence was highest during the first six months $(3 \cdot 4 / 100$ women) then fell progressively in each successive six-month period $(2 \cdot 0,1 \cdot 3$, 0.7 , and 0.4 per 100 women respectively) $\left(\chi^{2}\right.$ for trend $\left.=7.8 ; p<0.01\right)$. The risk of developing the disease was strongly related to age (table). At every time interval the cumulative rates were appreciably higher in the younger women and decreased as age increased $\left(\chi^{2}\right.$ for trend $\left.=7.3 ; p<0.01\right)$. Other factors that might predispose to the disease were investigated. Of women with pelvic inflammatory disease, $3(6 \%)$ reported a history of the disease, 14 $(25 \%)$ a history of abortion, and $6(11 \%)$ a difficult insertion. These results, however, were not significantly different from those in women without the disease $(3 \%, 20 \%$, and $9 \%$ respectively).

Cumulative rates for pelvic inflammatory disease per 100 women by age and duration of IUCD use. Numbers of cases given in parentheses

\begin{tabular}{|c|c|c|c|c|c|}
\hline \multirow{2}{*}{$\begin{array}{l}\text { Duration of } \\
\text { IUCD use } \\
\text { (months) }\end{array}$} & \multicolumn{4}{|c|}{ Age group (years) } & \multirow{2}{*}{$\begin{array}{l}\text { All ages } \\
(\mathrm{n}=871)\end{array}$} \\
\hline & $\begin{array}{c}16-19 \\
(n=61)\end{array}$ & $\begin{array}{c}20-24 \\
(n=413)\end{array}$ & $\begin{array}{c}25-29 \\
(\mathrm{n}=312)\end{array}$ & $\begin{array}{c}30-49 \\
(n=85)\end{array}$ & \\
\hline $\begin{array}{l}6 \\
12 \\
18 \\
24 \\
30\end{array}$ & $\begin{array}{r}5 \cdot 3(3) \\
9.4(5) \\
9 \cdot 4(5) \\
14 \cdot 2(7) \\
14 \cdot 2(7)\end{array}$ & $\begin{array}{l}3.7(13) \\
6.3(21) \\
8.6(26) \\
9.0(27) \\
9 \cdot 4(28)\end{array}$ & $\begin{array}{l}3 \cdot 2(9) \\
4.8(13) \\
6.1(16) \\
6.5(17) \\
7 \cdot 0(18)\end{array}$ & $\begin{array}{l}1 \cdot 2(1) \\
1 \cdot 2(1) \\
1 \cdot 2(1) \\
1 \cdot 2(1) \\
1 \cdot 2(1)\end{array}$ & $\begin{array}{l}3.4(26) \\
5.4(40) \\
6.6(48) \\
7.3(52) \\
7.7(54)\end{array}$ \\
\hline
\end{tabular}

\section{Comment}

Many studies have shown that the risk of pelvic inflammatory disease is greater in IUCD users than in non-users. ${ }^{2}$ Women with the disease are less likely to be using oral contraceptives ${ }^{2}{ }^{3}$ or mechanical methods ${ }^{2}$ than IUCDs. Our findings show that in a large sample of nulliparous women attending one centre, all of whom were using the same type of IUCD, the risk of the disease was further related to duration of use and to age. Our finding that the risk decreased progressively with duration of use is consistent with earlier reports.

The effect of age was striking. After two years 16 to 19 -year-olds had an infection rate more than 10 times that of 30 to 49 -year-olds. Gray, working from the data of Weström et al,,$^{2}$ also showed that age may be an important determinant of IUCD-related pelvic inflammatory disease, younger women being at higher risk than older women. It is not surprising that this effect is found, since a similar pattern exists in the general population. Hospital data show that the peak rate of the disease occurs in the 15-24 age group, and that this decreases progressively as age increases. ${ }^{5}$ This may be because younger rather than older women are more likely to be exposed to sexually transmitted infections. Since the rates of pelvic inflammatory disease are initially higher in young women, and IUCD use increases the overall risk of the disease, the greatest effect of the IUCD-associated disease is in this age group.

Since pelvic inflammatory disease may lead to infertility, we advise careful counselling before use of the IUCD by nulliparous women, especially the very young.

We thank Ms Ann McCulloch and Ms Walli Bounds for help in collecting the data and Ms Eve Roman for help in computing.

Requests for reprints should be addressed to Margaret Booth.

1 Guillebaud J. Pelvic inflammatory disease and IUCDs. British fournal of Family Planning 1978;4:25-30.

2 Weström L, Bengtsson LP, Mardh PA. The risk of pelvic inflammatory disease in women using intrauterine contraceptive devices as compared to non-users. Lancet 1976 ;ii:221-4.

${ }^{3}$ Eschenbach DA, Harnisch JP, Holmes KK. Pathogenesis of acute pelvic inflammatory disease: role of contraception and other risk factors. $A m \mathcal{F}$ Obstet Gynecol 1977;128:838-50.

4 Gray RH. Pelvic inflammatory disease and intrauterine contraceptive devices. Lancet 1976;ii:521.

5 Beral V. An epidemiological study of recent trends in ectopic pregnancy. Br F Obstet Gynaecol 1975;82:775-82.

(Accepted 11 April 1980)

Department of Medical Statistics and Epidemiology, London School of Hygiene and Tropical Medicine, London WC1E 7HT

MARGARET BOOTH, MSC, research fellow

VALERIE BERAL, MRCP, senior lecturer in epidemiology

Margaret Pyke Centre for Study and Training in Family Planning, London W1A 4HQ

JOHN GUILLEBAUD, FRCSED, MRCOG, medical director 